Pacific Journal of Mathematics

EXISTENCE, UNIQUENESS AND LIMITING BEHAVIOR OF
OLUTIONS OF A CLASS OF DIFFERENTIAL EQUATIONS IN

JOHN LAGNeS 


\title{
EXISTENCE, UNIQUENESS AND LIMITING BEHAVIOR OF SOLUTIONS OF A CLASS OF DIFFERENTIAL EQUATIONS IN BANACH SPACE
}

\author{
JOHN LAGNESE
}

Let $X$ be a Banach space (real or complex) and $A_{n}$ and $B$ be linear operators in $X$ with $D(B) \subseteq D\left(A_{n}\right), n=1,2, \cdots$. The following note is concerned with existence and uniqueness of solutions of the problem

$$
\frac{d}{d t}\left[\left(I-A_{n}\right) u(t)\right]-B u(t)=0, \quad(t>0), u(0)=u_{0},
$$

and the limiting behavior of these solutions as the operators $A_{n}$ tend to zero in a sense to be specified. We will show that for a large class of operators the problem (1.1) is well posed and that its solutions tend to the solution of the problem

$$
\frac{d u(t)}{d t}-B u(t)=0, \quad(t>0), u(0)=u_{0} \text {. }
$$

In particular, we obtain an extension to Banach spaces of a result of R. E. Showalter [5] to the effect that (1.1) is well posed when $X$ is a Hilbert space and $A_{n}$ and $B$ are maximal dissipative operators in $X$ which satisfy the algebraic condition

$$
\operatorname{Re}\left(\left(I-A_{n}\right) x, B x\right) \leqq 0, \quad x \in D(B) \leqq D\left(A_{n}\right) .
$$

In the next section we give sufficient conditions for (1.1) to be well posed. We note that these conditions do not guarantee that (1.2) is well posed. In $\S 3$ we show that if, in addition, $\left\{A_{n}\right\}$ tends to zero in a certain sense, then (1.2) is well posed and the solutions $u_{n}$ of (1.1) tend to the solution of (1.2). In particular, it will follow that if $A$ and $B$ are densely defined maximal dissipative operators in a Hilbert space and if (1.3) is satisfied with $A_{n}=n^{-1} A$, then

$$
\frac{d}{d t}\left[\left(I-n^{-1} A\right) u_{n}(t)\right]-B u_{n}(t)=0, \quad(t>0), \quad u_{n}(0)=u_{n} \in D(B),
$$

is well posed and as $n \rightarrow \infty, u_{n}$ converges strongly to the unique solution of (1.2). Two examples are discussed in $\S 4$.

We emphasize that throughout this paper it is assumed that $D(B) \subseteq D\left(A_{n}\right)$. The question of limiting behavior of solutions of (1.1) when $X$ is a Hilbert space, $A_{n}=n^{-1} A$ and $D(A) \subseteq D(B)$ has been considered previously [2], and it is interesting to compare the results of [2] with those of the present note in the case $D(A)=D(B)$. In [2] it was assumed that $A$ and $B$ were maximal dissipative operators 
arising from certain densely defined, strongly coercive sesequilinear forms and that $A$ was self-adjoint. On the other hand the algebraic condition (1.3) which is the most restrictive assumption of the present note, was not assumed in [2] and the convergence results are somewhat stronger than those obtained here. Thus while the results of [2] do not apply to perturbations of hyperbolic problems, they are in some respects more satisfactory as far as perturbations of parabolic problems are concerned when $D(A)=D(B)$. We note that the methods used here are completely different from those of [2].

2. Existence and uniqueness of solutions. A solution of the problem (1.1) is a function $u:[0, \infty) \rightarrow D(B)$ such that $\left(I-A_{n}\right) u \in$ $C([0, \infty) ; X) \cap C^{\prime}((0, \infty), X)$ and $(1.1)$ is satisfied. The initial condition in (1.1) is supposed to hold in the sense that $\left(\mathrm{I}-A_{n}\right) u(t) \rightarrow\left(I-A_{n}\right) u_{0}$ strongly in $X$ as $t \rightarrow 0_{+}$. While we will always assume that $I-A_{n}$ in invertible, the inverse need not be bounded and so we do not know in general that $u(t) \rightarrow u_{0}$ strongly in $X$.

Theorem 2.1. Let $X$ be a Banach space and $A_{n}$ and $B$ linear operators in $X$ which satisfy the following

$$
\begin{gathered}
I-A_{n} \text { is one-to-one. } \\
D(B) \subseteq D\left(A_{n}\right) .
\end{gathered}
$$

$\left\|x-A_{n} x-\zeta B x\right\| \geqq\left\|x-A_{n} x\right\|$ for all $x \in D(B)$ and $\zeta>0$.

$$
\text { For some } \zeta_{n}>0, \operatorname{Rg}\left(I-A_{n}-\zeta_{n} B\right)=X \text {. }
$$

Then for any $u_{0} \in D(B)$ the problem (1.1) has a unique solution $u(t)$ and

$$
\left\|\left(I-A_{n}\right) u(t)\right\| \leqq\left\|\left(I-A_{n}\right) u_{0}\right\|, t \geqq 0 .
$$

Proof. Set $\widetilde{A}_{n}=A_{n \mid D(B)}$ and $B_{n}=B\left(I-\widetilde{A}_{n}\right)^{-1}$ with $D\left(B_{n}\right)=$ $\operatorname{Rg}\left(I-\widetilde{A}_{n}\right)$. A function $u$ is a solution of (1.1) if and only if $\left(I-A_{n}\right) u=v \in C([0, \infty) ; X) \cap C^{\prime}((0, \infty) ; X)$ and

$$
\frac{d v(t)}{d t}-B_{n} v(t)=0,(t>0), v(0)=v_{0}
$$

where $v_{0}=\left(I-A_{n}\right) u_{0} \in D\left(B_{n}\right)$. From (2.3) we obtain

$$
\left\|y-\zeta B_{n} y\right\| \geqq\|y\|, y \in D\left(B_{n}\right), \zeta>0,
$$

which means that $B_{n}$ is a dissipative operator in $X$, and from (2.4) we have $\operatorname{Rg}\left(I-\zeta B_{n}\right)=X$ from some $\zeta>0$ (hence for all $\zeta>0$ ). From these facts it follows that $D\left(B_{n}\right)$ is dense in $X$ (Goldstein [1]; c.f. [4]). We may now apply the Lumer-Phillips theorem [3] to the 
effect that $B_{n}$ is the infinitesimal generator of a $\left(C_{0}\right)$-semigroup $\left\{e^{t B_{n}}: t \geqq 0\right\}$ of contractions on $X$. Thus for any $v_{0} \in D\left(B_{n}\right),(2.6)$ has a unique solution given by $v(t)=e^{t B_{n}} v_{0}$ and $|v(t)| \leqq\left|v_{0}\right|$. The conclusions of the theorem now follow by setting

$$
u(t)=\left(I-A_{n}\right)^{-1} e^{t B_{n}}\left(I-A_{n}\right) u_{0} .
$$

CoROLlaRY 2.1. Let $X$ be a Hilbert space and $A_{n}$ and $B$ be densely defined, maximal dissipative linear operators in $X$ such that $D(B) \subseteq D\left(A_{n}\right)$ and which satisfy (1.3). Then the conclusions of Theorem 2.1 hold. Moreover, $B \in C([0, \infty), X) \cap C^{\prime}((0, \infty) ; X)$ and $u(t) \rightarrow u_{0}$ strongly in $X$ as $t \rightarrow 0_{+}$.

Proof. Since $A_{n}$ is densely defined and maximal dissipative, $\left(I-A_{n}\right)$ is a bijection of $D\left(A_{n}\right)$ onto $X$ and $\left\|\left(I-A_{n}\right)^{-1}\right\| \leqq 1$. Also, R. E. Showalter proved [5] that under the stated hypotheses, $A_{n}+B$ is a densely defined, maximal dissipative operator in $X$. From this fact follows that $\operatorname{Rg}\left(I-A_{n}-B\right)=X$. For a Hilbert space, conditions (1.3) and (2.3) are equivalent. The conclusions of the corollary now follow from (2.7) and Theorem 2.1.

REMARK. Suppose (2.1)-(2.4) hold and that in addition there is a constant $C>0$ such that

$$
\left\|x-A_{n} x-\zeta B x\right\| \geqq C\left\|x-A_{n} x\right\|
$$

for each $x \in D(B)$ and all $\zeta$ with $\operatorname{Re}(\zeta)>0$. Then the semigroup $\left\{e^{t B_{n}}: t \geqq 0\right\}$ has a strong holomorphic extension into some sector $|\arg t|<\alpha$, and therefore (2.6) (respectively, (1.1)) is uniquely solvable for any $v_{0} \in X$ (respectively, $u_{0} \in D\left(A_{n}\right)$ ). In fact, since $B_{n}$ generates a $\left(C_{0}\right)$-semigroup of contractions, the open right half-plane lies in the resolvent set of $B_{n}$ and from (2.8) we obtain $\left\|\left(\lambda-B_{n}\right)^{-1}\right\| \leqq(C|\lambda|)^{-1}$ whenever $\operatorname{Re} \lambda>0$, which implies the desired conclusion. When $X$ is a Hilbert space, a sufficient condition for (2.8) is that all of the values of $z=\left(x-A_{n} x, B x\right)$ lie in some fixed sector

$$
|\arg z-\pi| \leqq \frac{\pi}{2}-\varepsilon, \quad \varepsilon>0 .
$$

To prove this, write $z=|z| e^{i \theta}$ and $\zeta=|\zeta| e^{i \phi}$. (2.8) is equivalent to

$$
\left(1-C^{2}\right)\left\|x-A_{n} x\right\|^{2}-2\left|\zeta\left\|\left.z|\cos (\phi-\theta)+| \zeta\right|^{2}\right\| B x \|^{2} \geqq 0\right. \text {. }
$$

If $|\theta-\pi| \leqq \pi / 2-\varepsilon$, there is a $\delta>0$ such that $\cos (\phi-\theta) \leqq 1-\delta$ for all $\phi \in(-\pi / 2, \pi / 2)$ and therefore

$$
\begin{aligned}
& (1-\delta)^{2}\left\|x-A_{n} x\right\|^{2}-2\left|\zeta\left\|\left.z|\cos (\phi-\theta)+| \zeta\right|^{2}\right\| B x \|^{2}\right. \\
& \quad \geqq(1-\delta)^{2}\left\|x-A_{n} x\right\|^{2}-2|\zeta|(1-\delta)\left\|x-A_{n} x\right\|\|B x\| \\
& \quad+|\zeta|^{2}\|B x\|^{2}=\left[(1-\delta)\left\|x-A_{n} x\right\|-|\zeta\||| B x\|]^{2} \geqq 0 .\right.
\end{aligned}
$$


Thus (2.8) holds with $C^{2}=2 \delta-\delta^{2}$.

3. Limiting behavior of solutions. We first prove that if $B$ is closed and $A_{n}$ tends to zero in a certain way then (1.2) is well posed.

THEOREM 3.1. Let $X$ be a Banach space and $A_{n}$ and $B$ be linear operators in $X$ which satisfy (2.1)-(2.4). Suppose in addition

$$
B \text { is closed. }
$$

$$
\lim _{n \rightarrow \infty} \sup _{\substack{x \in D(B) \\ x \neq 0}}\left\|A_{n} x\right\| /(\|B x\|+\|x\|)=0 .
$$

Then $B$ is the infinitesimal generator of a $\left(C_{0}\right)$-semigroup of contractions on $X$.

Proof. We have to show that $B$ is a dissipative operator such that $\operatorname{Rg}(I-B)=X$. From (2.3) and (3.2) we obtain, upon letting $n \rightarrow \infty$,

$$
\|x-\zeta B x\| \geqq\|x\|, x \in D(B), \zeta>0,
$$

and so $B$ is dissipative. For each $n$ and $\zeta>0, B_{n}$ is dissipative and $\operatorname{Rg}\left(I-\zeta B_{n}\right)=X$. Let $y \in X$ and $x_{n} \in D(B)$ such that

$$
x_{n}-A_{n} x_{n}-B x_{n}=y, \quad n=1,2, \cdots .
$$

By (2.3), $\left\|x_{n}-A_{n} x_{n}\right\| \leqq\|y\|$ and therefore $\left\{B x_{n}\right\}$ is bounded. Let

$$
C_{n}=\sup _{\substack{x \in D(B) \\ x \neq 0}}\left\|A_{n} x\right\| /(\|B x\|+\|x\|) .
$$

$C_{n} \rightarrow 0$ as $n \rightarrow \infty$ according to (3.2). From (3.3)

$$
\begin{aligned}
\left\|x_{n}\right\| & \leqq\left\|x_{n}-B x_{n}\right\|=\left\|y+A_{n} x_{n}\right\| \\
& \leqq\|y\|+C_{n}\left(\left\|B x_{n}\right\|+\left\|x_{n}\right\|\right)
\end{aligned}
$$

so that

$$
\left(1-C_{n}\right)\left\|x_{n}\right\| \leqq\|y\|+C_{n}\left\|B x_{n}\right\| .
$$

Hence $\left\{x_{n}\right\}$ is also bounded. It follows from (3.2) that $A_{n} x_{n} \rightarrow 0$ strongly in $X$ as $n \rightarrow \infty$. Therefore

$$
\begin{aligned}
\left\|x_{n}-x_{m}\right\| & \leqq\left\|\left(x_{n}-x_{m}\right)-B\left(x_{n}-x_{m}\right)\right\| \\
& \leqq\left\|A_{n} x_{n}-A_{m} x_{m}\right\| \longrightarrow 0
\end{aligned}
$$

as $n, m \rightarrow \infty$. Let $x=\lim x_{n}$. We have that $x_{n} \rightarrow x, B x_{n} \rightarrow x-y$. Since $B$ is closed, $x \in D(B)$ and $x-B x=y$, that is, $\operatorname{Rg}(I-B)=X$. This fact, together with the dissipativity of $B$, implies $D(B)$ is dense 
in $X$. The conclusion of the theorem now follows from the LumerPhillips theorem.

THEOREM 3.2. Let $X$ be a Banach space and $A_{n}$ and $B$ be linear operators in $X$ which satisfy (2.1)-(2.4), (3.1) and (3.2). Then as $n \rightarrow \infty, e^{t B_{n}} \rightarrow e^{t B}$ strongly and uniformly on bounded subsets of $[0, \infty)$.

Proof. We apply the Trotter convergence theorem [6]. To do this we show that for each $\zeta>0$,

$$
\lim _{n \rightarrow \infty}\left(I-\zeta B_{n}\right)^{-1}=(I-\zeta B)^{-1}
$$

in the uniform operator topology of $\mathscr{L}(X)(=$ the linear space of bounded linear operators on $X$ ).

We may write

$$
\begin{aligned}
\left(I-\zeta B_{n}\right)^{-1} & =\left(I-\zeta B\left(I-\widetilde{A}_{n}\right)^{-1}\right)^{-1} \\
& =\left(I-A_{n}\right)(I-\zeta B)^{-1}\left(I-A_{n}(I-\zeta B)^{-1}\right)^{-1} .
\end{aligned}
$$

For each $x \in X$,

$$
\begin{aligned}
\left\|A_{n}(I-\zeta B)^{-1} x\right\| & \leqq C_{n}\left(\left\|B(I-\zeta B)^{-1} x\right\|+\left\|(I-\zeta B)^{-1} x\right\|\right) \\
& \leqq C_{n}\left(1+\frac{2}{\zeta}\right)\|x\|
\end{aligned}
$$

Thus for all sufficiently large $n$,

$$
\left(I-A_{n}(I-\zeta B)^{-1}\right)^{-1}=\sum_{k=0}^{\infty}\left(A_{n}(I-\zeta B)^{-1}\right)^{k}
$$

and

$$
\left\|\left(I-A_{n}(I-\zeta B)^{-1}\right)^{-1}-I\right\| \leqq \sum_{k=0}^{\infty} C_{n}^{k+1}\left(1+\frac{2}{\zeta}\right)^{k+1}
$$

which tends to zero as $n \rightarrow \infty$. Therefore

$$
\lim _{n \rightarrow \infty}(I-\zeta B)^{-1}\left(I-A_{n}(I-\zeta B)^{-1}\right)^{-1}=(I-\zeta B)^{-1}
$$

in the uniform operator topology of $\mathscr{L}(X)$. From (3.6) we have

$$
\begin{aligned}
& \left\|A_{n}(I-\zeta B)^{-1}\left(I-A_{n}(I-\zeta B)^{-1}\right)^{-1}\right\| \\
& \quad \leqq C_{n}\left(1+\frac{2}{\zeta}\right)\left\|\left(I-A_{n}(I-\zeta B)^{-1}\right)^{-1}\right\| \\
& \quad \leqq \sum_{k=0}^{\infty} C_{n}^{k+1}\left(1+\frac{2}{\zeta}\right)^{k+1} \longrightarrow 0
\end{aligned}
$$

as $n \rightarrow \infty$. (3.4) now follows from (3.5), (3.7), and (3.8).

Theorem 3.3. Let $X$ be a Banach space and $A_{n}$ and $B$ be linear operators in $X$ which satisfy (2.1)-(2.4), (3.1) and (3.2). Suppose in 
addition that $\operatorname{Rg}\left(I-A_{n}\right)=X, n=1,2, \cdots$, and $\sup _{n}\left\|\left(I-A_{n}\right)^{-1}\right\|<$ $\infty$. Let $u_{0} \in D(B)$ and $u_{n}(t)$ be the unique solution of (1.1). Then as $n \rightarrow \infty, u_{n}(t) \rightarrow e^{t B} u_{0}$ strongly in $X$, uniformly on bounded subsets of $[0, \infty)$.

Proof. From (2.7) we obtain

$$
\begin{aligned}
& \left\|u_{n}(t)-e^{t B} u_{0}\right\| \leqq\left\|\left(I-A_{n}\right)^{-1}\left(e^{t B_{n}}-e^{t B}\right) u_{0}\right\| \\
& \quad+\left\|\left(I-A_{n}\right)^{-1} A_{n} e^{t B} u_{0}\right\|+\left\|\left(I-A_{n}\right)^{-1} e^{t B_{n}} A_{n} u_{0}\right\| \\
& \leqq \text { (const.) }\left[\left\|e^{t B_{n}} u_{0}-e^{t B} u_{0}\right\|+C_{n}\left(\left\|B u_{0}\right\|+\left\|u_{0}\right\|\right)\right]
\end{aligned}
$$

and the right side tends to zero as $n \rightarrow \infty$, uniformly on bounded subsets of $[0, \infty)$.

Corollary 3.1. Let $X$ be a Hilbert space and $A_{n}$ and $B$ be densely defined, maximal dissipative operators in $X$ such that $D(B) \cong$ $D\left(A_{n}\right)$ and which satisfy (1.3) and (3.2). Then for each $u_{0} \in D(B)$ the problem (1.1) has a unique solution $u_{n}$ and $u_{n}(t) \rightarrow e^{t B} u_{0}$ as $n \rightarrow$ $\infty$, uniformly on bounded subsets of $[0, \infty)$.

Proof. As noted in the proof of Corollary 2.1, $A_{n}$ and $B$ satisfy (2.1)-(2.4) and moreover, $\operatorname{Rg}\left(I-A_{n}\right)=X$ with $\left\|\left(I-A_{n}\right)^{-1}\right\| \leqq 1$. In addition $B$, being a densely defined, maximal dissipative operator in a Hilbert space, is closed. The corollary now follows from Theorem 3.3.

REMARK. When $A_{n}=n^{-1} A$, (3.2) is automatically satisfied provided $A$ and $B$ are closed operators with $D(B) \subseteq D(A)$. Thus in this case hypothesis (3.2) may be omitted in Corollary 3.1. In fact, as a rather well-known consequence of the closed graph theorem we have

$$
\|A x\| \leqq C(\|B x\|+\|x\|), \quad x \in D(B)
$$

where the constant $C$ does not depend on $x$. Therefore

$$
\sup _{\substack{u \in D \backslash B) \\ u \neq 0}}\left\|A_{n} x\right\| /(\|B x\|+\|x\|) \leqq C n^{-1} .
$$

4. Examples. As a first example we consider the problem

$$
\begin{aligned}
\frac{\partial}{\partial t}\left(u-a_{n}^{1}(x) u-a_{n}(x) \frac{\partial u}{\partial x}\right)-\left(b^{1}(x) u+b(x) \frac{\partial u}{\partial x}\right)=0, & \\
0<x<1, \quad t>0, &
\end{aligned}
$$

$$
u(x, 0)=u_{0}(x), \quad 0<x<1 ; u(0, t)=c u(1, t), \quad t>0,
$$

where $c$ is a complex constant satisfying certain conditions and the coefficients in (4.1) are real-valued and of class $C^{\prime}([0,1])$. Let $X$ be the complex Hilbert space $L_{2}(0,1)$ and $H_{2}^{1}(0,1)$ be the subclass of 
$L_{2}(0,1)$ consisting of those functions whose first derivative in the sense of distributions is again in $L_{2}(0,1)$. The norms in $X$ and in $H_{2}^{1}(0,1)$ will be denoted by $\|\cdot\|_{0}$ and $\|\cdot\|_{1}$ respectively and the inner product in $X$ by $(\cdot, \cdot)$; we have

$$
\|u\|_{1}=\left(\|u\|_{0}^{2}+\left\|\frac{d u}{d x}\right\|_{0}^{2}\right)^{1 / 2}, \quad u \in H_{2}^{1}(0,1) .
$$

Each function in $H_{2}^{1}(0,1)$ is continuous, i.e., coincides with a function in $C([0,1])$ up to a set of Lebesgue measure zero, and the injection of $H_{2}^{1}(0,1)$ into $C([0,1])$ is continuous.

We define operators $A_{n}$ and $B$ in $X$ as follows:

$$
D\left(A_{n}\right)=D(B)=\left\{u \in H_{2}^{1}(0,1): u(0)=c u(1)\right\}
$$

and for $u \in D\left(A_{n}\right)=D(B)$,

$$
A_{n} u=a_{n}^{1} u+a_{n} \frac{d u}{d x}, \quad B u=b^{1} u+b \frac{d u}{d x} .
$$

From our preceding remarks it is easy to see that $D(B)$ is a closed subspace of $H_{2}^{1}(0,1)$ and $D(B)$ is dense in $L_{2}(0,1)$.

By a solution of (4.1), (4.2) we mean a solution of (1.1) in which $A_{n}$ and $B$ are the operators defined above. In order to apply the theory developed in $\S \S 2$ and 3 to the problem (4.1) and (4.2) we shall have to verify in particular condition (1.3). Concerning this we have

Lemina 4.1. Suppose $a_{n} b \geqq 0$ and that

$$
\begin{gathered}
b^{1}-\frac{1}{2} \frac{d b}{d x}-a_{n}^{1} b^{1}+\frac{1}{2} \frac{d}{d x}\left(a_{n} b^{1}+a_{n}^{1} b\right) \leqq 0 ; \\
\alpha_{n}(1)-|c|^{2} \alpha_{n}(0) \leqq 0
\end{gathered}
$$

where $\alpha_{n}=b-a_{n} b^{1}-a_{n}^{1} b$. Then (1.3) is satisfied.

Proof. For $u \in D(B)$ we have

$$
\begin{aligned}
\operatorname{Re}\left(u-A_{n} u, B u\right)= & \int_{0}^{1}\left(b^{1}-a_{n}^{1} b^{1}\right)|u|^{2} d x-\int_{0}^{1} a_{n} b\left|\frac{d u}{d x}\right|^{2} d x \\
& +\operatorname{Re} \int_{0}^{1}\left(b-a_{n}^{1} b-a_{n} b^{1}\right) \bar{u} \frac{d u}{d x} d x .
\end{aligned}
$$

The following identity is easily obtained by an integration by parts: For $u \in D(B)$ and $f \in C^{\prime}([0,1])$,

$$
\operatorname{Re} \int_{0}^{1} f \bar{u} \frac{d u}{d u} d x=\frac{1}{2}\left(f(1)-|c|^{2} f(0)\right)|u(1)|^{2}-\frac{1}{2} \int_{0}^{1} \frac{d f}{d x}|u|^{2} d x .
$$

From this identity we obtain for $u \in D(B)$ 


$$
\begin{aligned}
\operatorname{Re}(u- & \left.A_{n} u, B u\right)=\frac{1}{2}\left(\alpha_{n}(1)-|c \cdot|^{2} \alpha_{n}(0)\right)|u(1)|^{2}-\int_{0}^{1} a_{n} b\left|\frac{d u}{d x}\right|^{2} d x \\
& +\int_{0}^{1}\left[b^{1}-\frac{1}{2} \frac{d b}{d x}-a_{n}^{1} b^{1}+\frac{1}{2} \frac{d}{d x}\left(a_{n}^{1} b+a_{n} b^{1}\right)\right]|u|^{2} d x \leqq 0 .
\end{aligned}
$$

REMARK. If $\left\{a_{n}\right\}$ and $\left\{a_{n}^{1}\right\}$ tend to zero in the topology of $C^{\prime}([0,1])$ and if for some $\varepsilon>0$ we have

$$
b^{1}-\frac{1}{2} \frac{d b}{d x} \leqq-\varepsilon, \quad b(1)-|c|^{2} b(0) \leqq-\varepsilon,
$$

then (4.3) and (4.4) are easily seen to be satisfied for all sufficiently large $n$.

Theorem 4.1. Assume (4.3) and (4.4), that $a_{n} b \geqq 0$ and $a_{n}^{2}+$ $b^{2}>0$. In addition suppose

$$
\begin{gathered}
a_{n}(1)-|c|^{2} a_{n}(0) \leqq 0 ; \\
a_{n}^{1}-\frac{1}{2} \frac{d a_{n}}{d x}<1, \quad 0 \leqq x \leqq 1 ;
\end{gathered}
$$

(4.7) There exists $\zeta_{n}>0$ such that

$$
c \exp \left[\int_{0}^{1} \frac{1-a_{n}^{1}(\xi)-\zeta_{n} b^{1}(\xi)}{a_{n}(\xi)+\zeta_{n} b(\xi)} d \xi \neq 1 .\right.
$$

Then the hypotheses of Theorem 2.1 are satisfied.

Thus, in particular, for each $u_{0} \in D(B)$ the problem (4.1), (4.2) has a unique solution.

THeOREM 4.2. Assume (4.3)-(4.5), that $a_{n} b \geqq 0$ and $b \neq 0$. In addition suppose

(4.8) $\left\{a_{n}\right\}$ and $\left\{a_{n}^{1}\right\}$ tend to zero in the topology of $C^{\prime}([0,1])$ as $n \rightarrow \infty$.

Then the hypotheses of Theorem 3.2 are satisfied for all sufficiently large $n$.

Theorem 4.3. Assume (4.3)-(4.5), (4.8) and that $a_{n} b>0$. Then the hypotheses of Theorem 3.3 are satisfied for all sufficiently large $n$.

Thus if $u_{n}$ is the unique solution of (4.1), (4.2), as $n \rightarrow \infty u_{n}(t)$ converges in $L_{2}(0,1)$ to the unique solution of

$$
\frac{\partial u}{\partial t}-b(x) \frac{\partial u}{\partial x}-b^{1}(x) u=0, \quad 0<x<1, \quad t>0,
$$




$$
u(x, 0)=u_{0}(x), \quad 0<x<1 ; \quad u(0, t)=c u(1, t), \quad t>0,
$$

uniformly on bounded subsets of $[0, \infty)$.

Proof of Theorem 4.1. We have already verified (2.3). To check (2.1) consider the equation

$$
u-A_{n} u=f \in X .
$$

Multiplying by $\bar{u}$ and integrating gives

$$
\int_{0}^{1}\left(1-a_{n}^{1}\right)|u|^{2} d x-\operatorname{Re} \int_{0}^{1} a_{n} \bar{u} \frac{d u}{d x} d x=\operatorname{Re} \int_{0}^{1} \bar{u} f d x
$$

and this may be written

$$
\begin{aligned}
\int_{0}^{1}\left(1-a_{n}^{1}\right. & \left.+\frac{1}{2} \frac{d a_{n}}{d x}\right)|u|^{2}=\frac{1}{2}\left(a_{n}(1)-|c|^{2} a_{n}(0)\right)|u(1)|^{2} \\
& +\operatorname{Re} \int_{0}^{1} \bar{u} f d x .
\end{aligned}
$$

From (4.5), (4.6) and (4.9) follows that $u=0$ if $f=0$.

We next verify (2.4). Let $f \in L_{2}(0,1)$. We have to solve

$$
u-A_{n} u-\zeta_{n} B u=\left(1-a_{n}^{1}-\zeta_{n} b^{1}\right) u-\left(a_{n}+\zeta_{n} b\right) \frac{d u}{d x}=f
$$

where $\zeta_{n}>0$ is to be determined.

Since $a_{n} b \geqq 0$ and $a_{n}^{2}+b^{2}>0$, we have $a_{n}+\zeta b \neq 0$ for every $\zeta>0$ and therefore (4.10) is equivalent to

where

$$
u(x)=k_{n} \exp \int_{0}^{x} K_{n}(\xi) d \xi+\int_{0}^{x} \widetilde{K}_{n}(x, \xi) f(\xi) d \xi
$$

$$
\begin{gathered}
K_{n}(\xi)=\left(1-a_{n}^{1}(\xi)-\zeta_{n} b^{1}(\xi)\right) /\left(a_{n}(\xi)+\zeta_{n} b(\xi)\right), \\
\widetilde{K}_{n}(x, \xi)=-\left[\exp \int_{\xi}^{x} K_{n}(\eta) d \eta\right] /\left(a_{n}(\xi)+\zeta_{n} b(\xi)\right) .
\end{gathered}
$$

The constant $k_{n}$ must be such that $u(0)=c u(1)$. This condition leads to

$$
k_{n}=k_{n} c \exp \int_{0}^{1} K_{n}(\xi) d \xi+c \int_{0}^{1} \widetilde{K}_{n}(1, \xi) f(\xi) d \xi
$$

and this equation is solvable for $k_{n}$ for arbitrary $f \in L_{2}(0,1)$ if and only if

$$
c \exp \int_{0}^{1} K_{n}(\xi) d \xi \neq 1 .
$$

This last condition is satisfied provided $\zeta_{n}$ is chosen according to condition (4.7). Thus (2.4) is satisfied. 
Proof of Theorem 4.2. We first note that (4.8) implies (4.6) for all sufficiently large $n$. Moreover, (4.7) is also satisfied for all large $n$ if $\left\{\zeta_{n}\right\}$ is any sequence of positive numbers which tends to zero. Thus conditions (2.1)-(2.4) are satisfied. That (3.1) and (3.2) also hold is a consequence of the inequality

$$
\|u\|_{1} \leqq K\left(\|B u\|_{0}+\|u\|_{0}\right), \quad u \in D(B)
$$

where the constant $K$ is independent of $u$. In fact, suppose (4.11) holds and $\left\{u_{n}\right\} \subset D(B), u_{n} \rightarrow u, B u_{n} \rightarrow v$ in $L_{2}(0,1)$. By (4.11), $\left\{u_{n}\right\}$ converges in $H_{2}^{1}(0,1)$. Since $D(B)$ is a closed subspace of $H_{2}^{1}(0,1)$ and $\left\|B u_{n}\right\|_{0} \leqq$ (const.) $\left\|u_{n}\right\|_{1}$ it follows that $u \in D(B)$ and $B u=v$, i.e., $B$ is closed. Moreover, we have

$$
\left\|A_{n} u\right\|_{0} \leqq \sup _{0 \leqq x \leqq 1}\left(\left|a_{n}(x)\right|+\left|a_{n}^{1}(x)\right|\right)\|u\|_{1}
$$

and therefore

$$
\sup _{\substack{u \in D(B) \\ u \neq 0}}\left\|A_{n} u\right\|_{0} /\left(\|B u\|_{0}+\|u\|_{0}\right) \leqq K \sup _{0 \leqq x \leqq 1}\left(\left|a_{n}(x)\right|+\left|a_{n}^{1}(x)\right|\right)
$$

which tends to zero as $n \rightarrow \infty$. Thus (3.2) is satisfied.

It only remains to prove (4.11). We have

$$
\|B u\|_{0}^{2}=\int_{0}^{1}\left(b \frac{d u}{d x}+b^{1} u\right)\left(b \frac{d \bar{u}}{d x}+b^{1} \bar{u}\right) d x .
$$

Using the inequality

$$
2|y z| \leqq \delta|y|^{2}+\frac{1}{\delta}|z|^{2}, \quad \delta>0
$$

we obtain

$$
\|B u\|_{0}^{2} \geqq \inf _{0 \leqq x \leqq 1}|b(x)|^{2}\left\|\frac{d u}{d x}\right\|_{0}^{2}-\varepsilon\left\|\frac{d u}{d x}\right\|_{0}^{2}-K_{\varepsilon}\|u\|_{0}^{2} .
$$

Choosing $\varepsilon=1 / 2 \inf _{0 \leqq x \leqq 1}|b(x)|^{2}$ leads to (4.11).

Proof of Theorem 4.3. We have only to verify that $\operatorname{Rg}\left(I-A_{n}\right)=$ $L_{2}(0,1), n \geqq N$, and

$$
\sup _{n \geqq N}\left\|\left(I-A_{n}\right)^{-1}\right\|<\infty .
$$

From (4.9) and the present hypotheses it follows that for all sufficiently large $n$,

$$
\frac{1}{2}\|u\|_{0}^{2} \leqq\left\|u-A_{n} u\right\|, \quad u \in D\left(A_{n}\right) .
$$

Let $f \in L_{2}(0,1)$. Since $a_{n} \neq 0$, the equation 


$$
u-A_{n} u=\left(1-a_{n}^{1}\right) u-a_{n} \frac{d u}{d x}=f
$$

is equivalent to

$$
u(x)=k_{n} \exp \int_{0}^{x} \frac{1-a_{n}^{1}}{a_{n}}(\xi) d \xi+F_{n}(x)
$$

where $F_{n}(x)$ is a known function and the constant $k_{n}$ must be such that $u(0)=c u(1)$. This is possible for arbitrary $f \in L_{2}(0,1)$ if and only if

$$
c \exp \int_{0}^{1} \frac{1-a_{n}^{1}(\xi)}{a_{n}(\xi)} d \xi \neq 1
$$

and this last condition is obviously satisfied for all sufficiently large $n$ in view of (4.8). Thus $\operatorname{Rg}\left(I-A_{n}\right)=X, n \geqq N$, and the proof is complete.

ExAMPle 2. We consider, for $n=1,2, \cdots$, the problem

$$
\begin{gathered}
\frac{\partial}{\partial t}\left(u-\frac{1}{n} \frac{\partial u}{\partial x}\right)-\left(b(x) u+\frac{\partial^{2} u}{\partial x^{2}}\right)=0, \quad 0<x<1, \quad t>0, \\
u(x, 0)=u_{0}(x), \quad 0<x<1, \\
u(0, t)=c u(1, t), \quad \bar{c} \frac{\partial u}{\partial x}(0, t)=\frac{\partial u}{\partial x}(1, t), \quad t>0 .
\end{gathered}
$$

The function $b$ is real-valued and of class $C^{\prime}([0,1])$ and $c$ is a complex constant. Let $X=L_{2}(0,1), D\left(A_{n}\right)$ be as in the first example and $A_{n}=1 / n d / d x$. Let $H_{2}^{2}(0,1)$ be the set of functions in $L_{2}(0,1)$ whose first and second distributional derivatives are in $L_{2}(0,1)$ and set

$$
\begin{gathered}
D(B)=\left\{u \in H_{2}^{2}(0,1): u(0)=c u(1), \bar{c} \frac{d u}{d x}(0)=\frac{d u}{d x}(1)\right\}, \\
B u=b u+\frac{d^{2} u}{d x^{2}}, \quad u \in D(B) .
\end{gathered}
$$

The norm in $H_{2}^{2}(0,1)$ is denoted by $\|\cdot\|_{2}$ and defined by

$$
\|u\|_{2}=\left(\|u\|_{0}^{2}+\mid \frac{d u}{d x}\left\|_{0}^{2}+\right\| \frac{d^{2} u}{d x^{2}} \|_{0}^{2}\right)^{1 / 2} .
$$

Each function in $H_{2}^{2}(0,1)$ is of class $C^{\prime}([0,1])$ and the injection of $H_{2}^{2}(0,1)$ into $C^{\prime}[(0,1)]$ is continuous. It follows that $D(B)$ is a closed subspace of $H_{2}^{2}(0,1)$, is dense in $L_{2}(0,1)$ and as in the first example it is not difficult to verify that

$$
\|u\|_{2} \leqq K\left(\|B u\|_{0}+\|u\|_{0}\right), \quad u \in D(B) .
$$

Let $B^{*}$ be the adjoint of $B$. As is well-known, $D\left(B^{*}\right) \subset H_{2}^{2}(0,1)$ 
and, since $b+d^{2} / d x^{2}$ is a formally self-adjoint differential operator,

$$
B^{*} v=b v+\frac{d^{2} v}{d x^{2}}, \quad v \in D\left(B^{*}\right) .
$$

We show that $B^{*}=B$. If $v \in D\left(B^{*}\right)$ then for all $u \in D(B)$ we have

$$
\begin{aligned}
(B u, v)= & \int_{0}^{1}\left(b u+\frac{d^{2} u}{d x^{2}}\right) \bar{v} d x=\frac{d u}{d x}(0)(\bar{c} \bar{v}(1)-\bar{v}(0)) \\
& -u(1)\left(\frac{d \bar{v}}{d x}(1)-c \frac{d \bar{v}}{d x}(0)\right)+\left(u, B^{*} v\right) .
\end{aligned}
$$

Since the first two terms on the right must vanish for all $u \in D(B)$ we have $v(0)=c v(1), \bar{c}(d v / d x)(0)=(d v / d x)(1)$, that is, $v \in D(B)$. Thus $B^{*} \subseteq B$. On the other hand, $(B u, v)=(u, B v)$ for all $u$ and $v$ in $D(B)$ so that $B$ is symmetric. Hence $B$ is self-adjoint.

THEOREM 4.4. Suppose $b \leqq 0, d b / d x \leqq 0$ and

$$
b(1)-|c|^{2} b(0) \geqq 0 \text {. }
$$

Then the hypotheses of Corollary 3.1 are satisfied.

Thus for each $n$ and $u_{0} \in D(B)$ the problem (4.12)-(4.14) has a unique solution $u_{n}$ and, as $n \rightarrow \infty, u_{n}(t)$ converges in $L_{2}(0,1)$ to the solution of

$$
\begin{gathered}
\frac{\partial u}{\partial t}-\frac{\partial^{2} u}{\partial x^{2}}-b(x) u=0, \quad 0<x<1, \quad t>0, \\
u(x, 0)=u_{0}(x), \quad 0<x<1, \\
u(0, t)=c u(1, t), \quad \bar{c} \frac{\partial u}{\partial x}(0, t)=\frac{\partial u}{\partial x}(1, t), \quad t>0,
\end{gathered}
$$

uniformly on bounded subsets of $[0, \infty)$.

Proof of Theorem 4.4. We have for $u \in D(B)$

$$
(B u, u)=\int_{0}^{1} b|u|^{2} d x-\int_{0}^{1}\left|\frac{d u}{d x}\right|^{2} d x \leqq 0 .
$$

$B$ is therefore a self-adjoint, dissipative operator and, consequently, maximal dissipative. We also have

$$
n \cdot \operatorname{Re}\left(A_{n} u, u\right)=\frac{1}{2}\left(1-|c|^{2}\right)|u(1)|^{2}, \quad u \in D\left(A_{n}\right) .
$$

Since $b \leqq 0$ and $d b / d x \leqq 0$ we have $b(1) \leqq b(0) \leqq 0$. Since also $b(1) \geqq$ 
$|c|^{2} b(0)$ it follows that $|c|^{2} \geqq 1$. Thus $A_{n}$ is dissipative and one easily proves as in the first example that $R g\left(I-A_{n}\right)=X$.

Next we verify (1.3). We have for $u \in D(B)$

$$
\begin{aligned}
n \cdot \operatorname{Re}\left(A_{n} u, B u\right)= & \operatorname{Re} \int_{0}^{1} \frac{d u}{d x}\left(b \bar{u}+\frac{d^{2} \bar{u}}{d x^{2}}\right) d x \\
= & \frac{1}{2}\left(b(1)-|c|^{2} b(0)\right)|u(1)|^{2}-\frac{1}{2} \int_{0}^{1} \frac{d b}{d x}|u|^{2} d x \\
& +\frac{1}{2}\left|\frac{d u}{d x}(0)\right|^{2}\left(|\bar{c}|^{2}-1\right) \geqq 0 .
\end{aligned}
$$

(1.3) follows from this inequality and the fact that $B$ is dissipative. Finally, (3.2) is an immediate consequence of (4.15).

\section{REFERENCES}

1. J. A. Goldstein, Lectures on Semigroups of Nonlinear Operators, Tulane University Lecture Notes, 1972.

2. J. Lagnese, Approximation of solutions of differential equations in Hilbert space,

J. Math. Soc. Japan, 25 (1973), 132-143.

3. G. Lumer and R. S. Phillips, Dissipative operators in a Banach space, Pacific J. Math., 11 (1961), 679-698.

4. R. S. Phillips, Dissipative operators and hyperbolic systems of partial differential equations, Trans. Amer. Math. Soc., 90 (1959), 193-254.

5. R. E. Showalter, Equations with operators forming a right angle, Pacific J. Math., 5 (1973), 357-362.

6. H. F. Trotter, Approximation of semigroups of operators, Pacific J. Math., 8 (1958), 887-919.

Received May 30, 1972 and in revised form February 20, 1973.

GEORGETOWN UNIVERSITY 



\section{PACIFIC JOURNAL OF MATHEMATICS}

\section{EDITORS}

RICHARD ARENS (Managing Editor)

University of California

Los Angeles, California 90024

\section{J. DUGUNDJI}

Department of Mathematics University of Southern California Los Angeles, California 90007

D. Gilbarg and J. Milgram

Stanford University

Stanford, California 94305

University of Washington
Seattle, Washington 98105

ASSOCIATE EDITORS
E. F, BECKENBACH
B. H. NEUMANN
F. WOLF
K. Yoshida

\section{SUPPORTING INSTITUTIONS}

\author{
UNIVERSITY OF BRITISH COLUMBIA \\ CALIFORNIA INSTITUTE OF TECHNOLOGY \\ UNIVERSITY OF CALIFORNIA \\ MONTANA STATE UNIVERSITY \\ UNIVERSITY OF NEVADA \\ NEW MEXICO STATE UNIVERSITY \\ OREGON STATE UNIVERSITY \\ UNIVERSITY OF OREGON \\ OSAKA UNIVERSITY
}

\author{
UNIVERSITY OF SOUTHERN CALIFORNIA \\ STANFORD UNIVERSITY \\ UNIVERSITY OF TOKYO \\ UNIVERSITY OF UTAH \\ WASHINGTON STATE UNIVERSITY \\ UNIVERSITY OF WASHINGTON \\ * * * * \\ AMERICAN MATHEMATICAL SOCIETY \\ NAVAL WEAPONS CENTER
}

The Supporting Institutions listed above contribute to the cost of publication of this Journal, but they are not owners or publishers and have no responsibility for its content or policies.

Mathematical papers intended for publication in the Pacific Journal of Mathematics should be in typed form or offset-reproduced, (not dittoed), double spaced with large margins. Underline Greek letters in red, German in green, and script in blue. The first paragraph or two must be capable of being used separately as a synopsis of the entire paper. Items of the bibliography should not be cited there unless absolutely necessary, in which case they must be identified by author and Journal, rather than by item number. Manuscripts, in duplicate if possible, may be sent to any one of the four editors. Please classify according to the scheme of Math. Rev. Index to Vol. 39. All other communications to the editors should be addressed to the managing editor, or Elaine Barth, University of California, Los Angeles, California, 90024.

100 reprints are provided free for each article, only if page charges have been substantially paid. Additional copies may be obtained at cost in multiples of 50 .

The Pacific of Journal Mathematics is issued monthly as of January 1966. Regular subscription rate: $\$ 72.00$ a year (6 Vols., 12 issues). Special rate: $\$ 36.00$ a year to individual members of supporting institutions.

Subscriptions, orders for back numbers, and changes of address should be sent to Pacific Journal of Mathematics, 103 Highland Boulevard, Berkeley, California, 94708.

PUBLISHED BY PACIFIC JOURNAL OF MATHEMATICS, A NON-PROFIT CORPORATION

Printed at Kokusai Bunken Insatsusha (International Academic Printing Co., Ltd.), 270, 3-chome Totsuka-cho, Shinjuku-ku, Tokyo 160, Japan.

Copyright (C) 1973 by Pacific Journal of Mathematics Manufactured and first issued in Japan 


\section{Pacific Journal of Mathematics}

\section{Vol. 53, No. $2 \quad$ April, 1974}

Kenneth Abernethy, On characterizing certain classses of first countable spaces by

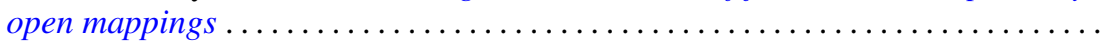

Ross A. Beaumont and Donald Lawver, Strongly semisimple abelian groups .......

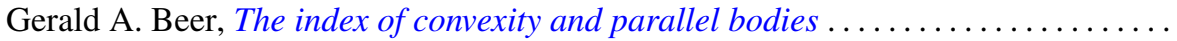

Victor P. Camillo and Kent Ralph Fuller, On Loewy length of rings ..............

Stephen LaVern Campbell, Linear operators for which $T^{*} T$ and $T T^{*}$ commute.

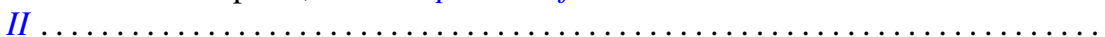

Charles Kam-Tai Chui and Philip Wesley Smith, Characterization of a function by

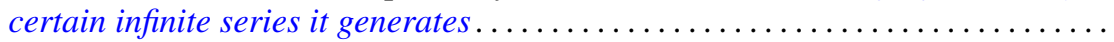

Allan L. Edelson, Conjugations on stably almost complex manifolds . ...........

Patrick John Fleury, Hollow modules and local endomorphism rings . . ..........

Jack Tilden Goodykoontz, Jr., Connectedness im kleinen and local connectedness in

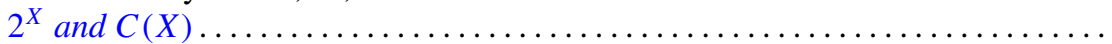

Robert Edward Jamison, II, Functional representation of algebraic intervals .......

Athanassios G. Kartsatos, Nonzero solutions to boundary value problems for

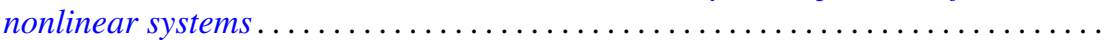

Soon-Kyu Kim, Dennis McGavran and Jingyal Pak, Torus group actions on simply

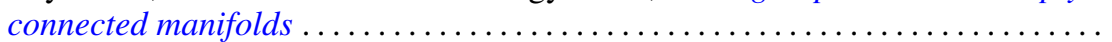

David Anthony Klarner and R. Rado, Arithmetic properties of certain recursively

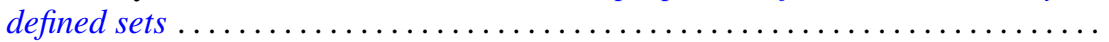

Ray Alden Kunze, On the Frobenius reciprocity theorem for square-integrable

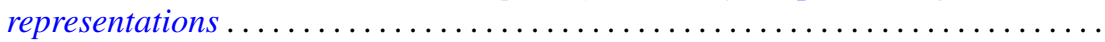

John Lagnese, Existence, uniqueness and limiting behavior of solutions of a class of differential equations in Banach space...

Teck Cheong Lim, A fixed point theorem for families on nonexpansive mappings Lewis Lum, A quasi order characterization of smooth continua

Andy R. Magid, Principal homogeneous spaces and Galois extensions . .

Charles Alan McCarthy, The norm of a certain derivation ..... . .

Louise Elizabeth Moser, On the impossibility of obtaining $S^{2} \times S^{1}$ by elementary surgery along a knot. .

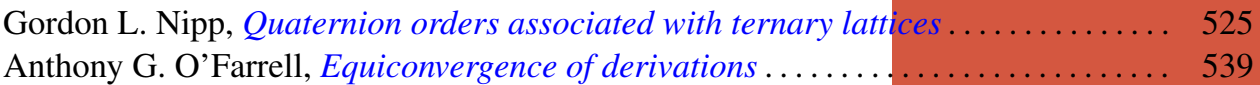

Dorte Olesen, Derivations of $A W^{*}$-algebras are inner . . . . . . . . . . . . . . . 555

Dorte Olesen and Gert Kjærgaard Pedersen, Derivations of $C^{*}$-algebras have

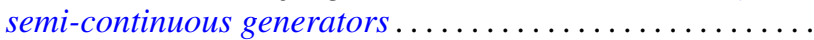

Duane O’Neill, On conjugation cobordism.

Chull Park and S. R. Paranjape, Probabilities of Wiener paths crossing differentiable

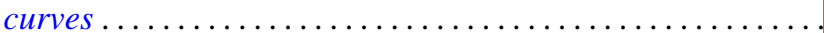

Edward Ralph Rozema, Almost Chebyshev subspaces of $L^{1}(\mu$;

Lesley Millman Sibner and Robert Jules Sibner, A note on the Atiyah-Bott fixed

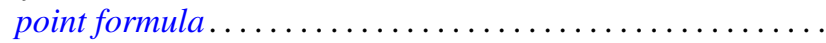

Betty Salzberg Stark, Irreducible subgroups of orthogonal groups generated by

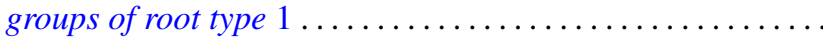

N. Stavrakas, A note on starshaped sets, $(k)$-extreme points and the half ray

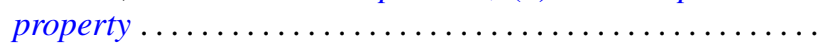

Carl E. Swenson, Direct sum subset decompositions of $Z \ldots \ldots$ 